\title{
For the love of Greece
}

King Ludwig I of Bavaria was a lifelong Hellenophile whose son Otto became king of Greece in 1832 after the country was freed from Turkish rule. Ludwig commissioned Carl Rottmann to produce 23 paintings celebrating contemporary and ancient Greece for his palace gardens in Munich.

The exhibition 'Ten Tons Hellas', to run at the New Pinakothek in Munich until 29 April, brings together 14 of these works - each weighing $400 \mathrm{~kg}$ - for the first time since the Second World War. But scientific examination of the paintings has revealed that Rottmann did not blindly follow the dictates of his powerful king.

The commission had specified that Rottmann should work with encaustic, a newly revived technique involving the mixing of pigments with melted wax or resins. Spectacular examples of encaustic murals had recently been unearthed at Pompeii, their dazzling colours barely touched by centuries of winter rain. The encaustic technique was laborious and risky, involving heating at different stages of painting to

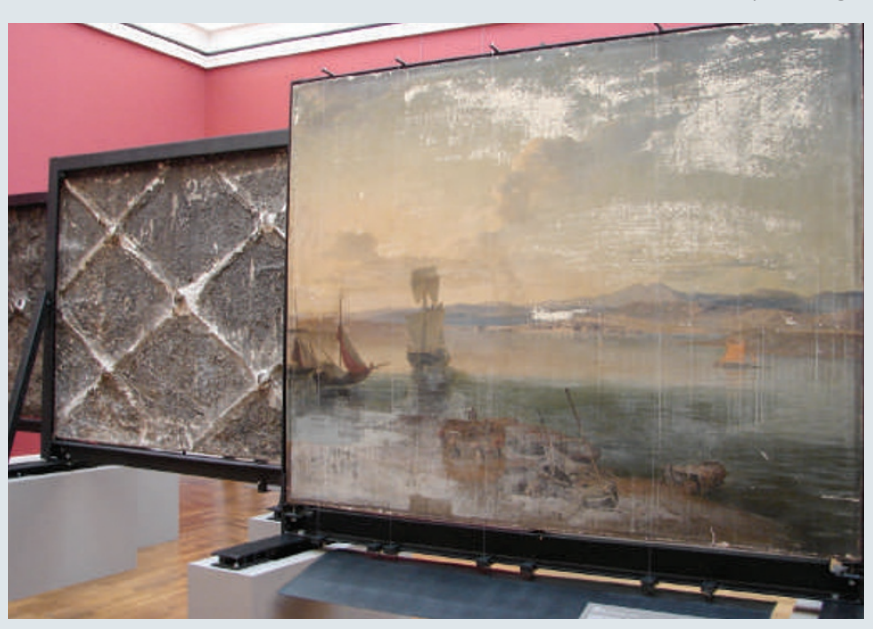

melt the resins. And because its revival was guided by the rather ambiguous writings of ancient scholars such as Pliny, it was still rather experimental.

Researchers at the Doerner Institute, housed in the New Pinakothek, examined some of the paintings. They found that by the time he was on the third painting,
Rottmann was experimenting with different methods to refine the encaustic technique. He soon abandoned all pretence and worked with a more conventional style of oil painting.

Ludwig had also dictated that the works be painted on moveable slabs. The researchers' $X$-ray analysis revealed welded iron support frames (shown here) - a technology developed for the railway industry - incorporating a network of wires to hold the layers of mortar and plaster. After the paintings were completed, they were set into the walls of a gallery in the New Pinakothek when it opened in 1853. Being so heavy, they remained in the gallery while other works were removed for safekeeping during the war. Stored in a basement, they were badly damaged by bombs in 1944 .

In the new display, the paintings are once again mounted into the plaster walls to give the intended character of murals.

\section{The pleasure principle}

\author{
The Science of Orgasm \\ by Barry R. Komisaruk, Carlos Beyer-Flores \\ $\&$ Beverly Whipple \\ Johns Hopkins University Press: 2006 \\ 280 pp. $\$ 25, € 16.50$
}

\section{Tim D. Spector}

The three academic authors of The Science of Orgasm - a neurophysiologist, a hormone physiologist and a sexologist - promise in the preface to take a different perspective from recent books exploring sexual behaviour and orgasm. Instead they focus on the physiology and pathology of ejaculation and orgasm in the context of bodily changes, health implications, dysfunction, ageing, pleasure and the nervous system. The publisher's blurb states that the book, which includes a glossary, sporadic definitions in the text and a meaty 45 pages of references, is accessible to lay readers.

The result is a bit of a pot-pourri. Although good in parts, the book lacks continuity and the authors do justice to only a few of their stated areas. They pose major problems for themselves by trying to cover too much and targeting both academics and lay readers - they certainly fail to deliver for the latter. Another problem is their loose definition of 'orgasm'. About a third of the book is related to sexual drive and desire, which includes much work on rodents and primates. These animals clearly ejaculate, but there is little supporting evidence (with the exception of a few primates) that they orgasm as humans do. Confusingly, the authors usually consider male and female orgasm together and seem to assume, based on a single study, that male and female orgasms are indistinguishable.

The title The Science of Orgasm sounds as if it should include all the key facets. I am clearly biased - but do genetic influences warrant only three lines in 300-odd pages? They also omit any real mention of human variation. Why might only one in three women reach orgasm regularly, and why do so few men have anorgasmia? Other female topics surprisingly given little space are the contraceptive pill, hormone replacement therapy and placebo effects on orgasms, as well as potential new treatments for sexual dysfunction, such as PDE5 inhibitors, oxytocin sprays and testosterone patches. Even more odd is the lack of discussion of the science around the existence of the G-spot and female ejaculation - particularly as one of the authors, Beverly Whipple, was one of the $\mathrm{G}$-spot pioneers in the 1980s.

The book gets bogged down in lengthy descriptions of hormone action, neuropharmacology and chronic diseases that read like a dull, albeit important, student textbook. There are some useful sections on the surprising and apparently real benefits of herbal remedies, such as ginseng, ginkgo and mixtures such as ArginMax. But the book only comes alive after about 200 pages with anecdotal stories of subjects who, after surgery, electrostimulation and epileptic seizures, report having orgasms in their feet, while asleep or while visiting the physiology lab.

In my view, the best part of the book is the neurochemistry of the orgasm. Studies of paraplegic women clearly show the importance in female orgasm of multiple complex neural pathways such as the vagus nerve. Functional brain imaging is an exciting area for study and (despite poor-quality pictures) the authors present the latest findings of multiple areas of brain activity during orgasm - which make any simplistic dopamine (stimulatory)-serotonin (inhibitory) mode of action unlikely. They postulate a central role for areas such as the cingulate cortex, which is also where pain is perceived - linking pain and orgasm as related sensory processes. Orgasms apparently alter pain perception and increase pain thresholds, and this link may explain bizarre reports of women having orgasms during childbirth. However, just when I was ready for the truth - a clear definition of orgasm and where it arises in the brain - I was told it was not a reflex, only a perception of neural activity and, even worse, probably a form of diffuse consciousness in an as yet undiscovered fifth dimension. After such a careful, slow build-up of teasing and tantalizing data, I was definitely left frustrated - and wanting more.

Tim D. Spector is professor of genetic epidemiology, King's College London, London SE1 7EH, UK. 